\title{
Accounting in Cloud
}

\author{
Jana Singerová*
}

\begin{abstract}
:
Cloud computing is a new technological trend that since the last decade brings challenges in computed accounting, such as a significant reduction of running cost, together with unrestricted access to data from anywhere and anytime. Cloud accounting software enables its users a real time access to business finances, easy set up and easy use, access to information from anywhere, work with sales force, to synchronize instantly with bank, make tax returns precise and effortless. Cloud computing offers a short implementation time and low initial costs and it is offered by ERP providers in the SaaS (Software as a Service) mode. As an essential condition for massive expansion is generally considered availability of access to the high frequency internet. As accounting data are very valuable, security, such as encryption of data, granting access to the data and backups are necessary conditions to ensure their proper treatment. The aim of this article is to identify key advantages and disadvantages and milestones of such a solution.
\end{abstract}

Key words: Accounting information systems; ERP; Integration; Cloud accounting.

JEL classification: M15, M41.

\section{Introduction}

The role of accounting is to satisfy information needs of its users and to deliver relevant and reliable information necessary for their decision-making. To achieve this goal, financial statements shall provide true and fair representation of the economic reality. The relevance of accounting information depends on the quality of financial reporting standards used in the preparation of financial statements; the reliability is co-determined by the integrity of processing of accounting records in the accounting system.

Today, computer-based accounting is a standard. Since 1970s, the computing development has been constantly increasing and nowadays allows real time processing and transfer of accounting data. Development of information systems in general and accounting information systems in particular has begun in the 1980s - simple bookkeeping on standalone computers, followed by an expansion of accounting systems that ran on PCs linked to the network. Consequently, with expansion and increasing speed of internet connections there appeared new

Jana Singerova; University of Economics in Prague, Faculty of Finance and Accounting, Department of Financial Accounting and Auditing, W. Churchill sq. 4, 13067 Prague 3, Czech Republic, <xsinj900@vse.cz>.

The article is processed as an output of a research project Impact of the changes in IFRS on financial statements quality under the registration number F1/91/2017. 
options of how to plug into the information systems - laptops, smartphones and tablets. In the past decade there came the cloud computing, offering access software and storage using internet, rather than physically installed applications and stored data within the computer. NIST (National Institution of Standards and Technologies) defines cloud computing as follows: "Cloud computing is a model for enabling ubiquitous, convenient, on-demand network access to a shared pool of configurable computing resources (e.g., networks, servers, storage, applications, and services) that can be rapidly provisioned and released with minimal management effort or service provider interaction" (Mell and Grance, 2011). Cloud computing provides companies and their accountants with faster and better access to accounting systems and information in real time and online, which makes accounts' preparation process more timely and efficient. The ERP system, through its embedded, standardized practices, could be in itself considered as a vehicle of conformity (Caglio, 2003).

The primary accounting function remains, i.e. on a cash basis measuring balances and monitor movements in assets and equity, modes of financing and measuring the company effectiveness. However, management decision-making based on the online access to the information system has become easier and more user friendly and it is also supported by available graphics, tables and charts (Christauskas and Miseviciene, 2012). ERP becomes one of the most important instruments through which firms can gain advantages over their competitors (Trott and Hoecht, 2004).

Acquisition of any new information system, be it the ERP system (Enterprise Resource Planning) or an Accounting information system, is time and resource demanding exercise and even when project management is applied during the implementation stage in order to reduce the related risks, more than $50 \%$ of implementations end up with exceeded budget, time schedule or both. Cloud accounting offers significant savings in incurred costs and time compared to the time- and resource-demanding acquisition of any new information, accounting or ERP system. Since 2014, ERP cloud platforms more than doubled from $10 \%$ to $23 \%$ in 2016 (Panorama Consulting, 2016). The aim of the paper is to assess the main factors influencing adoption of cloud accounting compared to on-premise accounting. The paper is organised as follows: chapter 2 is summarizing literature review; as the cloud computing and cloud accounting are quite new concepts, the literature sources are mainly from academic studies. The core of this study is chapter 3, containing explanation of cloud computing principles, current situation worldwide (with a focus on the EU), identification of factors influencing the decision-making process related to adoption of cloud accounting and concludes with a discussion of differences between an in-house accounting approach and the cloud-based accounting. 


\section{Literature Review}

Cloud computing has a large potential to become an innovation platform for new products and services. For small and medium sized enterprises (SMEs) that are an important part of the EU economy it is interesting due to the job creation, saving of investment costs and benefiting from gaining access to new technologies and services, including software updates. Large companies, institutions and governments are examining cloud computing as an important cost saving option to reduce expenditures on IT infrastructure and services and ongoing maintenance costs. Overall, cloud computing is expected to have a positive impact on the economic growth (OECD, 2014).

To grant a high level of security, security issues need to be addressed seriously. This includes proper selection of hardware components, encryption of data, preparation and testing of a disaster recovery plan, scalability of cloud by virtualization technologies, protection of the guest operating system ahead of any external attacks, securing applications and access to the cloud (Chraibi et al., 2013). (Allahverdi, 2017) identified low costs, easy access and applied high security standards as the main benefits data security, need for online access and data secrecy as the main weakness, real time access to data, integration and use in mobile applications as the main opportunity and security violation and legal barriers as the threats.

While the computing as a service (SaaS) is here to stay, it remains difficult to establish a verifiable basis for service providers and customers to reconcile resource accounting, leading to undesirable outcomes for both providers, who suffer to accurately justify their costs, and customers, who cannot verify the actual usage of the platform (Chen et al., 2013). Incorrect attribution of resource consumption reduces customer's cost-effectiveness and as customers have limited visibility to the infrastructure, systematic approach for verifiable resource accounting is necessary (Sekar and Maniatis, 2011), (Götze et al., 2011).

Accounting in cloud is similar to outsourcing, in terms of purchase one of the major business process in the company. As most users of cloud computers are concerned about the system and data security, internal controls and the auditing process are clear and Statement on Auditing Standards (SAS 70) is applied (Hui Du and Yu Cong, 2010).

From the tax perspective, cloud accounting allows accountants to complete jobs faster and with lower internal costs, which has a positive impact on the client satisfaction. If the electronic reporting is supported by the government and a range of online services and mobile applications, both individual and business taxpayers are targeted (Hossack, 2015).

Cloud accounting seems to be more suitable for small and medium size companies (SME's), rather than large companies. However, small companies are slower than 
large companies to adopt new technologies. The main limiting factor is finance. Cloud accounting systems can help increase processing capacity and grow business (Christauskas and Miseviciene, 2012).

\section{Methodology, Analysis and Discussion}

\subsection{Methodology}

This paper uses a comparative analysis approach. Key data resources are previously collected public data, information and analyses of various authorities, both Czech and European statistical offices. Some comparative data have been provided by an independent research company (Panorama Consulting, 2016). While processing the contribution, there were adopted the methods of description, deduction, analytics comparison and literature review.

\subsection{Comparative analysis}

Starting from the 1960s, the first information systems primarily focused on Material Requirements Planning (MRP). The main area was planning of material purchases. In the 1970s, there followed MRP II which allowed not only purchasing, but also production planning and production control. In the 1970s appeared first information systems enabling automatic entry of repetitive accounting records directly into the general ledger. Processing of transactions in the information systems was time consuming. This is the beginning of Enterprise Resource Planning (ERP) systems. The real boom, however, is visible in the 1990s (Worster et al., 2011).

ERP processes information on all business processes. ERP integrates and automatizes large number of processes such as planning, production, sales and distribution, purchasing, property management and accounting. Besides the main goal to automate the processes, the second objective was to increase the overall effectivity. ERP provides users with an online access to the information needed for their daily managerial tasks. Due to the integrity of the system, data are entered just once, which significantly reduces costs and the number of mistakes and increases the managerial control (Trott and Hoecht, 2004). ERP is multifunctional system that integrates the main corporate activities (Ko Hsu et al., 2006). Transactions processed in each module generate accounting transactions.

The main ERP providers are currently SAP (Germany), Oracle (USA), Microsoft (USA), Infor and Epicor (USA). Together SAP, Oracle and Microsoft have a market share of $55 \%$. However, industrial solutions vary and the most offered solutions are production, distribution, transportation, telecommunication, energy, services and sales. 
New technologies caused changes in the methods of how the accounting systems work. From batch inputs and batch processing of data the systems moved along to the real time processing. Each transaction has a direct impact on the relevant reports, which enables immediate control of the posted transactions. Systems, next to the standard financial statements (balance sheet, income statement, cash flow statement, statement of changes in equity) allow dynamic creation of customdesigned reports and statements and export to table processors (MS Excel, MS Access). Common feature is a display of the original transaction directly from the reports (simply by double clicking to the item which detail is being shown), which again significantly improves the process of control and enables to make an immediate correction. The advantage of austere accounting system is in its simplicity and user friendliness, and therefore it is suitable for small companies with simple agendas (Christauskas and Miseviciene, 2012). Once the company growths and its processes become more complex, an upgrade to the ERP solution becomes a necessity. When the upgrade is performed within the same provider, the knowledge of the particular environment is obvious an advantage.

Over the last decade, there appeared a new technology - cloud computing (internet base computing that provides shared computing processing resources and data to computers and other devices on demand).

Cloud computing is determined with five features:

- It is service based, where interfaces enable automated services to the customer and technologies are tailored to the customer needs. Service feature is based on the service level and IT outcomes,

- Has scalability and elasticity enabling capacity scaling up and down with demands of the customer,

- It is shared, where services share a pool of resources, which allows use with maximum efficiency. Resources can serve multiple needs for multiple consumers at the same time,

- It is metred by use, where services are tracked with usage metrics to enable multiple payment models, including different pricing plans,

- Use of internet technologies, such an internet identifiers, formats and protocols. (Stamford, 2009).

Cloud computing enables to transpose accounting and ERP systems to cloud environment in three types of services:

- SaaS model alias Software as a Service, when users access the systems via web browser but have neither control over the cloud infrastructure nor over applications. The only changes a user can make are individual settings within a specific application 
- IaaS alias Infrastructure as a Service, when the user has no control over cloud infrastructure but has a control over applications and storage.

- PaaS (Platform as a Service), which allows customers to develop, run and manage application, it may include facilities for application design and development and testing. This model allows a configuration for hosting. PaaS can be public (server management is done by the provider), private (installed or downloaded in the company's data centre) or hybrid (mix of public and private deployments) (Teach, 2016).

SaaS is often used by small and medium size companies; large companies use private clouds or dedicated servers in data centres. The development in cloud is rapid, on premise solution declined dramatically between 2014 and 2015 due to increase of SaaS solution in 2015. In 2016, on-premise solution remains at $56 \%$ (Fig. 1); meanwhile the cloud ERP is increasing at the expense of SaaS (Panorama Consulting, 2016).

\section{Fig. 1 ERP platform development in $2014-2016$}

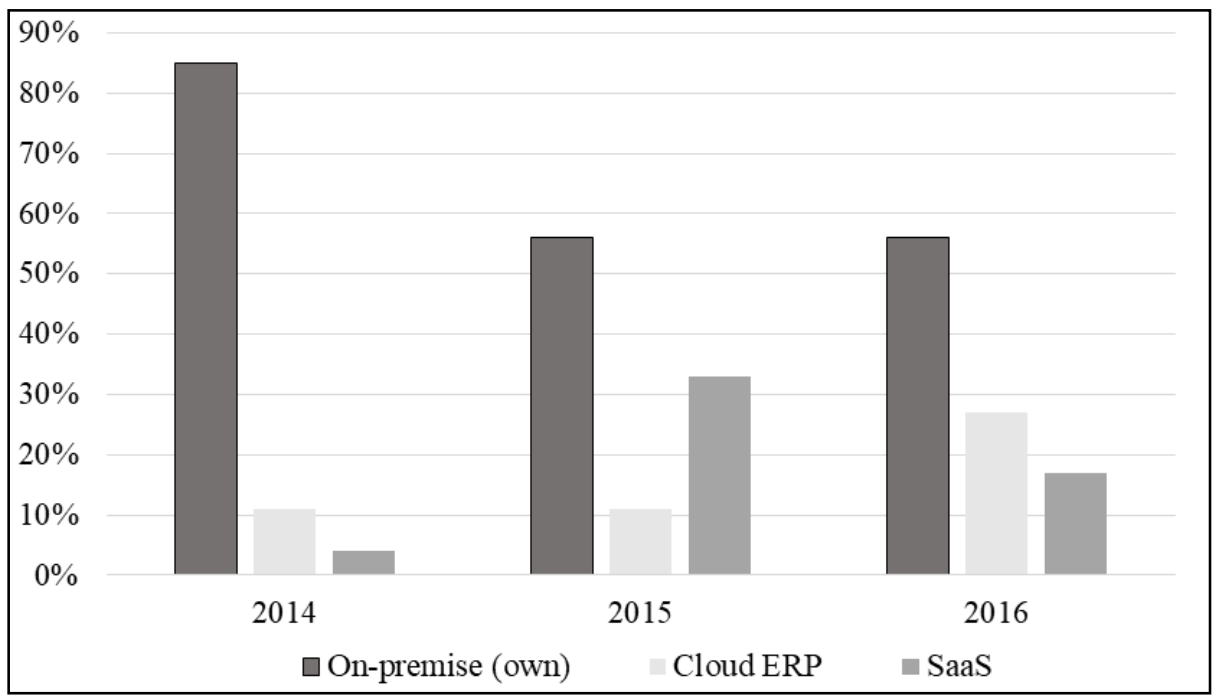

Source: Panorama Consulting, author's computations.

Increasing development of cloud computing is influenced by several factors: security of services and infrastructures demanding significant resources, investments to IT training and the development, backups and securing existing backups requiring storage outside the cloud, investments to servers' acquisition, increasing speed of internet connection and last but not least availability of mobile access to the application anytime and anywhere. Although the on-premise applications remain still a major force, cloud computing solutions have in 2016 
increased to $27 \%$ and SaaS has increased to $17 \%$ (Panorama Consulting, 2016). Increase in cloud computing is mainly drawn by SAP and Oracle, the two main players on the market (Tab. 1). Related cost reductions vary with some companies reporting up to $60 \%$ cost saving. Cloud computing solutions for ERP are available as an all-in-one solution covering all company processes, which significantly speeds up implementation (up to 3 months) and still guarantees functionality for all business processes and agendas, which can be easily adjusted to new requirements and changes in business. Total costs for running ERP on cloud are also influenced by the possibility to flexibly modify the number of licences. The most common reasons for abstaining from adoption of the cloud computing solution are security $(29 \%)$, risk of losing data $(9 \%)$ and lack of information (16\%) (Panorama Consulting, 2016).

Tab. 1 Total \& cloud revenue FY 2017 vs. 2016 - market leaders (mil USD)

\begin{tabular}{lrrrr}
\hline $\begin{array}{l}\text { Legend 1 } \\
\text { column }\end{array}$ & \multicolumn{1}{l}{$\begin{array}{l}\text { FY 2017 total } \\
\text { revenue }\end{array}$} & \multicolumn{1}{l}{$\begin{array}{l}\text { FY 2017 } \\
\text { cloud revenue }\end{array}$} & \multicolumn{1}{l}{$\begin{array}{l}\text { FY 2016 total } \\
\text { revenue }\end{array}$} & \multicolumn{1}{l}{$\begin{array}{l}\text { FY 2016 } \\
\text { cloud revenue }\end{array}$} \\
\hline Oracle & 37,047 & 2,853 & 37,728 & 4,571 \\
Microsoft & 89,950 & 27,440 & 85,320 & 25,042 \\
SAP SE* & 28,153 & 4,523 & 26,474 & 4,525 \\
\hline
\end{tabular}

Source: Financial statements 2017 (SAP, Oracle, SAP SE), author's computations.

Note: SAP SE figures have been recalculated from EUR to USD by exch. rate 1.2 (as of Jan 1, 2017). 
Fig. 2 High speed internet access \& financial/accounting application in cloud (EU countries) in January 2018

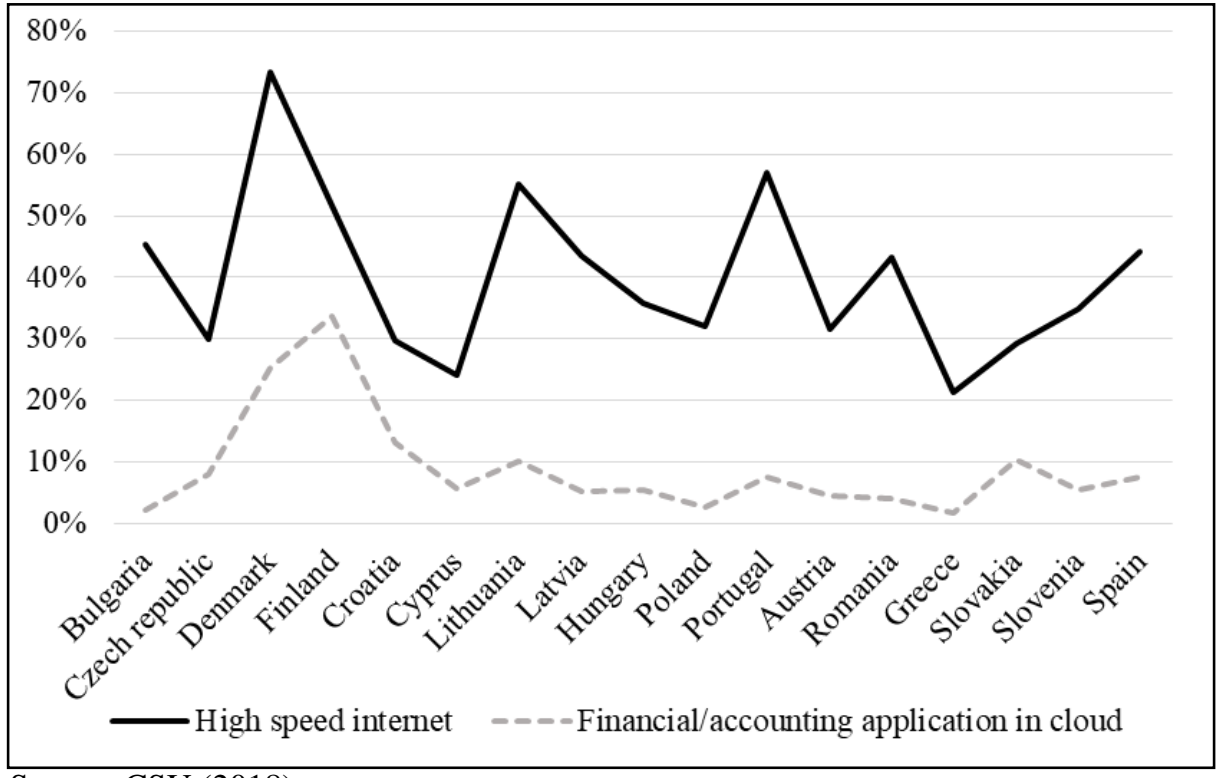

Source: CSU (2018).

Increasing popularity of cloud computing is driven by several factors. Legislative and regulatory supports solve any conflicts between customers and providers when problems such a disaster or a hack occurs. Governmental support, such as egovernment, enables to better predict legal environment, make more transparent legal and tax processes together with more effective public services online through one-stop platform, which was reported in 2016 in 90 countries worldwide (UN EGovernment Survey, 2016). Broadband subscription (both fixed and wireless) is a key element influencing cloud computing. In the EU (by January 2018), 96.6\% companies had an access to internet, high speed internet $(>30 \mathrm{Mb} / \mathrm{sec})$ was available to $38.4 \%$ companies. Fig. 2 shows in detail access to high speed internet and financial, resp. accounting, applications running in cloud (both private and public) in the EU countries as of January 2018 (CSU, 2018).

Cost saving is recognized as another important factor, which is consider during the decision-making phase. For in-house implementations, length of implementation is (on average) $14-21$ months and much resources are necessary to allocate. According the Panorama Consulting research for years 2012-2015, in companies with annual turnover of less than USD 300 million and budget with the total project cost $6.5 \%$ of the annual turnover, the approved budget is exceeded in more than $54 \%$ and time schedule is exceeded in more than $66 \%$ (for detail see Tab. 2). In contrary, cloud accounting shows a cost saving of up to $60 \%$, the average 
implementation length is between $3-5$ months (in-house implementation average length is 17.3 months).

Tab. 2 Total costs and length of implementation in $2012-2015$

\begin{tabular}{lrrrrr}
\hline Year & Cost (mil \$) & $\begin{array}{l}\text { \% exceeding } \\
\text { budget }\end{array}$ & $\begin{array}{l}\text { Implementation } \\
\text { in months }\end{array}$ & $\begin{array}{l}\text { \% exceeding } \\
\text { time schedule }\end{array}$ & $\begin{array}{l}\text { Fulfilled } \\
\text { expectation } \\
\text { from less } \\
\text { than half }\end{array}$ \\
\hline 2015 & 3.8 & 57 & 21.1 & 57 & 46 \\
2014 & 4.5 & 55 & 14.3 & 75 & 41 \\
2013 & 2.8 & 54 & 16.3 & 72 & 66 \\
2012 & 7.1 & 53 & 17.8 & 61 & 60 \\
\hline
\end{tabular}

Source: Panorama Consulting, author's computations.

Security issues such data privacy and confidentiality are recognized as a factor which needs to be addressed by e.g. access control to the different services or selective encryption of the data, providing a proper data privacy.

Cloud computing brought changes to auditing procedures. As the focus is on information governance, IT management, network, data, contingency and encryption controls, auditors should have the appropriate knowledge of these areas and (as cloud computing depends on web services) they should also have at least a basic understanding of Organization for the Advancement of Structured Information Standards (OASIS) Web Services Security Standards. (ISACA, 2014). ISACA (ISACA, 2014) defines the main components of risks as follows:

- greater dependency on third parties,

- increased risk in aggregated data centres,

- increased reliance on independent assurance processes,

- increased complexity of compliance with laws and regulations,

- reliance on the internet as the primary conduit to the enterprise's data,

- security issues with a public environment,

- location across international boundaries,

- legal issues relating to differing laws in hosting countries may put data at risk.

Auditors need to develop audit objectives, which cover key areas, such an identity and data management, data protection, associated technological risks, operational processes, policies, procedures, roles and responsibilities.

Availability is the major benefit for cloud customers, but service and data availability can be threatened by outside (and inside) hardware attacks, like DDoS (Distributed Denial of Service Attacks), which make the system unavailable 
(Chraibi et al., 2013). Summary of different conditions and features, both onpremise accounting and cloud accounting, shows Table 3.

Tab. 3 Total costs and length of implementation in $2012-2015$

\begin{tabular}{|c|c|c|}
\hline Accounting system & On-premise & Cloud (SaaS) \\
\hline Licence & Initial costs required & Covered by SaaS \\
\hline Hardware & Initial costs required & $\begin{array}{l}\text { Platform is covered by SaaS, } \\
\text { user's devices to be purchased }\end{array}$ \\
\hline Length of implementation & $17-24$ months in average & 3 months in average \\
\hline Contract with provider & N/A & Very important \\
\hline Access & Access rights to be customized & Access rights to be customized \\
\hline Access online & To be customized & Genuine attribute of cloud \\
\hline Internet connection & $\begin{array}{l}\text { Necessary only for online } \\
\text { access }\end{array}$ & Indispensable condition for use \\
\hline Data security & $\begin{array}{l}\text { Risks related data thefts and } \\
\text { burglary by employees }\end{array}$ & $\begin{array}{l}\text { Sharing data with third party is } \\
\text { an security risk (thefts, } \\
\text { burglary) }\end{array}$ \\
\hline Backup & Local setup and maintenance & Covered by SaaS \\
\hline Data storage & Local PC/local servers & Cloud servers \\
\hline Cost of storing data & $\begin{array}{l}\text { Capital expenditure }+ \text { operating } \\
\text { expenditure }\end{array}$ & $\begin{array}{l}\text { Capital expenditure covered by } \\
\text { SaaS, operation expenditure low }\end{array}$ \\
\hline IT resources & High labour costs & Low labour costs (less staff) \\
\hline Bandwidth & N/A & $\begin{array}{l}\text { If exceeded, can incurred } \\
\text { additional costs }\end{array}$ \\
\hline Legislative compliance & To be customized & Covered by SaaS \\
\hline Online tax reporting & To be customized & Covered by SaaS \\
\hline Level of customization & Individual & Very low \\
\hline Internal control processes & To be customized & Easy to setup \\
\hline Managerial information & Reports need to be customized & Online access \\
\hline
\end{tabular}

Source: own elaboration.

Benefits and risks associated with cloud accounting from the perspective of designers, auditors and users shows the SWOT analysis in Fig 3. 


\section{Fig. 3 SWOT analysis of benefits and risks associated with cloud accounting}

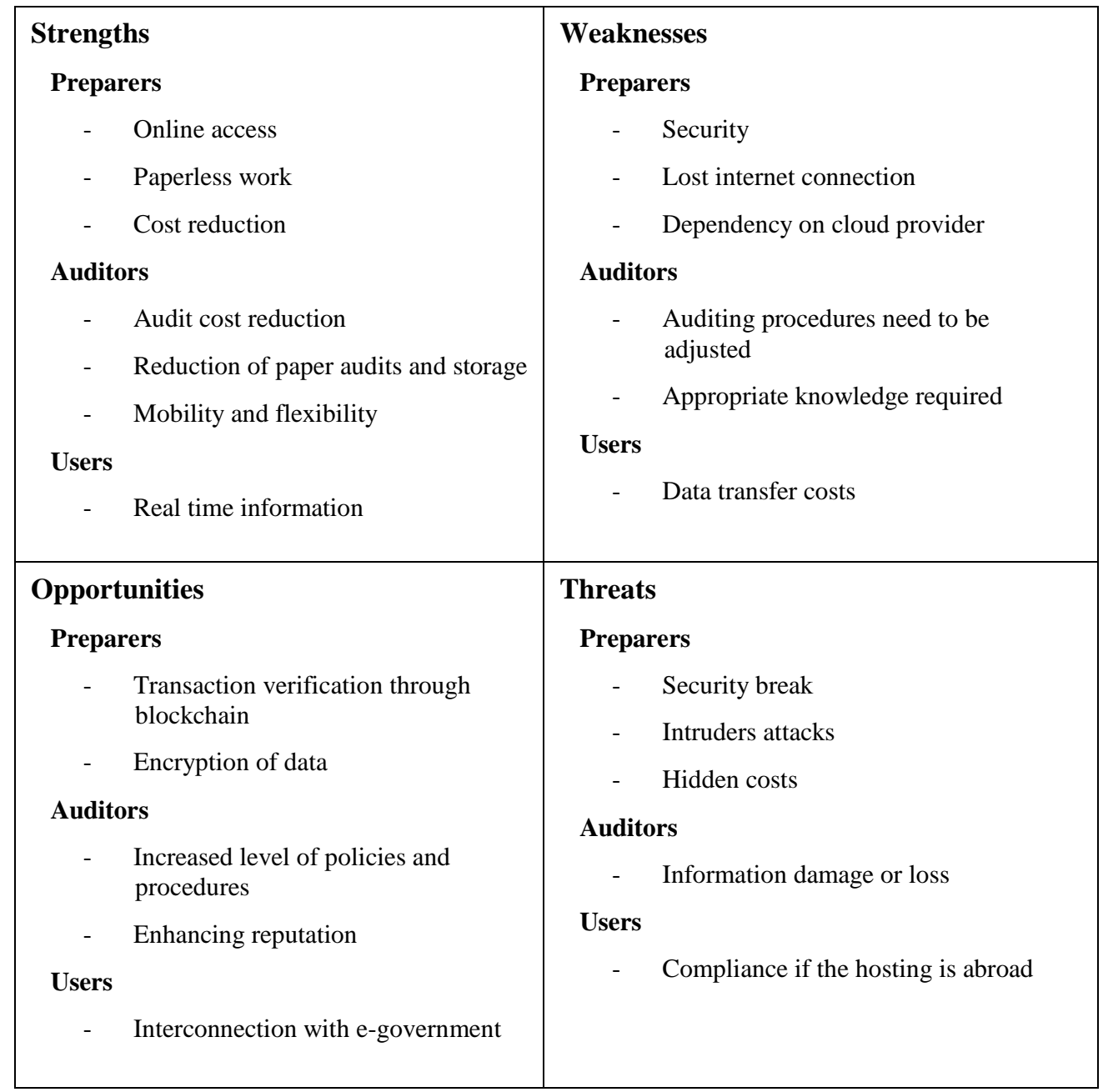

Source: own elaboration.

\subsection{Discussion}

Cloud accounting as a product within cloud computing becomes a viable option to in-house solutions mainly due to significant cost savings and a reduction of the implementation phase, which generates further cost savings. Although cloud computing grows constantly over the last decade, various levels of penetration can be found worldwide. Europe leads and coming closer to the market maturation, Africa is still lagging behind (United Nations, 2016). Table 4 shows detailed decomposition of cloud services used by the selected EU countries. Volume of 
financial or accounting applications run in cloud vary from very low in Greece, Bulgaria, Poland (up to $3 \%$ ) to the relatively high percentage in Slovakia, Lithuania and Croatia $(10-13 \%)$. Denmark and Finland are far away from the EU average with $25.3 \%$, respectively $33.8 \%$ of financial or accounting applications run in cloud.

Tab. 4 Overview of services performed in cloud - EU countries - Jan 2018* (in \%)

\begin{tabular}{|c|c|c|c|c|c|c|}
\hline Country & $\begin{array}{l}\text { Cloud } \\
\text { computing } \\
\text { in total }\end{array}$ & Email & Office SW & $\begin{array}{l}\text { Data } \\
\text { storage }\end{array}$ & $\begin{array}{l}\text { Fin./Acc. } \\
\text { Appl. }\end{array}$ & $\begin{array}{l}\text { In-house } \\
\text { applications }\end{array}$ \\
\hline Austria & 21.00 & 11.60 & 8.10 & 14.40 & 4.60 & 4.00 \\
\hline Bulgaria & 8.00 & 5.80 & 3.90 & 5.40 & 2.30 & 1.60 \\
\hline Croatia & 31.20 & 25.20 & 16.10 & 19.20 & 13.10 & 6.40 \\
\hline Cyprus & 21.70 & 16.30 & 12.50 & 13.90 & 5.60 & 4.70 \\
\hline $\begin{array}{l}\text { Czech } \\
\text { Rep. }\end{array}$ & 22.00 & 17.00 & 10.60 & 13.10 & 8.10 & 3.90 \\
\hline Denmark & 50.50 & 36.50 & 27.00 & 35.40 & 25.30 & 17.00 \\
\hline Finland & 65.60 & 50.00 & 37.50 & 41.60 & 33.80 & 10.20 \\
\hline Greece & 11.00 & 8.00 & 4.50 & 6.80 & 1.80 & 2.30 \\
\hline Hungary & 16.30 & 10.70 & 8.30 & 9.30 & 5.50 & 4.80 \\
\hline Latvia & 12.00 & 8.30 & 4.70 & 7.30 & 5.10 & 1.70 \\
\hline Lithuania & 23.20 & 17.60 & 9.90 & 13.30 & 10.20 & 9.00 \\
\hline Poland & 10.00 & 7.00 & 4.30 & 6.30 & 2.70 & 2.00 \\
\hline Portugal & 22.60 & 18.20 & 10.60 & 12.40 & 7.50 & 6.00 \\
\hline Romania & 10.80 & 7.60 & 4.30 & 4.80 & 4.10 & 2.10 \\
\hline Slovakia & 22.20 & 18.30 & 11.80 & 11.70 & 10.40 & 5.60 \\
\hline Slovenia & 22.10 & 13.50 & 10.90 & 11.90 & 5.50 & 4.30 \\
\hline Spain & 23.50 & 17.70 & 10.00 & 16.90 & 7.50 & 6.80 \\
\hline
\end{tabular}

Source: CSU (2018), own layout.

Note: * included are only countries disclosing detailed figures.

For further development and customer adoption of accounting applications run in cloud, there are certain recognized key elements such access to high speed internet and possibility to access applications through mobile devices. Covered security issues allow customers to benefit from cloud computing. 
Increase in the volume of cloud solutions shows that vendors believe in cloud accounting application on the SaaS platform. The main players have released their software packages, nevertheless accounting firms use accounting software that is installed on-premises (Drew, 2015). From the vendor's perspective, the market niche is not negligible, because the cloud computing is borderless. From the perspective of customers, the influencing factors, like access to broadband subscription and legal regulation, need time to be prepared and installed. The governmental support is also an important factor, though highly dependent upon political situation in each individual country. From the perspective of auditors, it is important to understand the system, the way how it is accessed, managed and controlled (Hui Du and Yu Cong, 2010). From the perspective of users, internal users such as managers can benefit from access to the data from anywhere and anytime while external users will be reliant on the information given. Online access to financial reports can be governed by the XBRL reporting standards, which are mandatory in many countries.

On-premise accounting allows users to have tailor-made systems (or an extensive ERP system) fulfilling all user's requirements regardless to external conditions, such as the internet access. Conservative customers may prefer on-premise accounting due to the data and access security issues.

\section{Conclusion}

The rapid development of cloud technologies creates new business opportunities and possibilities for customers in many areas of the core business processes. Interaction with portable devices, such as laptops, tables and smart phones enables access to company data anytime and anywhere. Cloud computing processing has become one of the most important developments that have recently emerged within accounting information systems (Akar, 2012).

Integration of accounting information systems into cloud systems introduces many advantages and opportunities compared to traditional systems (Allahverdi, 2017). According to (Mahoney, 2013), while the cost of traditional information technologies of businesses forms $68 \%$ of the total general expenditures, for cloud computing processing this rate is $9 \%$. In this study, benefits such a cost savings and short implementation periods were recognized as the key elements for customers in their decision-making process. On the other hand, the security and service quality are necessary to evaluate. Legal framework and regulations are important to avoid possible future problems, when hack attacks or disasters happen. In countries where accounting and taxation is based on one-stop platform, this technology is a key driver. Tax work and compliance-based accounting is rapidly becoming "commoditised" (Hossack, 2015). Change in platform from inhouse to cloud solution cannot change the role of the accounting information 
systems as a base for providing the financial information for decision-making to internal and external users, and therefore auditors will need to assess the risks associated with cloud accounting and they must gain knowledge of the new environment (Hui Du and Yu Cong, 2010).

Future research shall investigate cloud accounting from the perspective of providers, as cloud seems to be a great business opportunity, and from the perspective of customers simplifying tax returns, especially in countries where egovernment is established.

\section{References}

Akar, E., 2012. Factors Affecting the Adoption of Cloud Computing. The 19th International Business Information Management Association Conference, Barcelona.

Allahverdi, M., 2017. Cloud Accounting Systems and a Swot Analysis. The Journal of Account \& Finance, Special Issue, 92-105. Available from: $<$ http://journal.mufad.org.tr/attachments/article/910/ISAF2017-special-Issue. pdf\#page=95>. [7 January 2018].

Caglio, A., 2003. Enterprise Resource Planning systems and accountants: towards hybridization? European Accounting Review 1, 123-153. DOI: 10.1080/ 0963818031000087853.

Chen, C., Maniatis, P., Perrig, A., Vasudevan, A., Sekar, V., 2013. Towards Verifiable Resource Accounting for Outsourced Computation. In: Proceedings of the 9th ACM SIGPLAN/SIGOPS International Conference on Virtual Execution Environments, VEE '13. ACM, New York, USA, 167-178. DOI: 10.1145/ 2517326.2451546.

Chraibi, M., Harroud, H., Maach, A., 2013. Classification of Security Issues and Solutions in Cloud Environments. In: Proceedings of International Conference on Information Integration and Web-Based Applications \& Services, IIWAS '13. ACM, New York, USA, 560-564. DOI: 10.1145/2539150.2539222.

Christauskas, C., Miseviciene, R., 2012. Cloud - Computing Based Accounting for Small to Medium Sized Business. Debesų Kompiut. Pagrịsta Apskaita Maž. Ir Vidut. Liet. Imonėms 23, 14-21. DOI: 10.5755/j01.ee.23.1.1220.

Drew, J., 2015. Accounting firms moving slowly toward cloud. Journal of Accountancy 219, 1-6. Available from: <https://search-proquestcom.zdroje.vse.cz/docview/1660937315?accountid=17203>. [7 January 2018].

Götze, J., Fleuren, T., Reuther, B., Müller, P., 2011. Extensible and Scalable Usage Accounting in Service-oriented Infrastructures Based on a Generic Usage Record Format. In: Proceedings of the 6th International Workshop on Enhanced 
Web Service Technologies, WEWST '11. ACM, New York, USA, 16-24. DOI: 10.1145/2031325.2031328.

Hossack, S., 2015. Cloud-based accounting and productivity tools for practitioners and taxpayers. Taxation in Australia 50, 265-267. Avaible from: <https://searchproquest.com.zdroje.vse.cz/docview/814876588?accountid=17203>. [ 7 January 2018].

Hui Du, Yu Cong, 2010. Cloud Computing, Accounting, Auditing, and Beyond. The CPA Journal 80, 66-70. Avaible from: <https://search-proquestcom.zdroje.vse.cz/docview/814876588?accountid=17203>. [7 January 2018].

ISACA, 2014. Controls and assurance in cloud: using COBIT 5 Available from: $<$ https://www.isaca.org/Pages/FileDownload.aspx?file=http://www.isaca.org/Kno wledge-Center/Research/Documents/Controls-and-Assurance-in-the-Cloud-UsingCOBIT-5-AP_res_Eng_0414.doc\&referrer=http://www.isaca.org/KnowledgeCenter/Research/ResearchDeliverables/Pages/Controls-and-Assurance-in-theCloud-Using-COBIT-5.aspx\&regnum=428422>. [3 January 2018].

Mahoney, S. M., 2013. The Economics of Using Cloud Accounting Systems. Brittenford Syst. Available from: <http://www.brittenford.com/blog/theeconomics-of-using-cloud-accounting-systems/>. [2 January 2018].

OECD, 2014. Cloud Computing: The Concept, Impacts and the Role of Government Policy. DOI: 10.1787/5jxzf4lcc7f5-en.

Oracle - Financial Reporting - Quarterly Reports. Available from: <http:// investor.oracle.com/financial-reporting/quarterly-reports/default.aspx $>$. [23 January 2018].

Panorama Consulting, 2016. Panorama ERP 2016.pdf.

SAP Q4 2017 Quarterly Statement, 2017. Available from: <https://www.sap.com/investors/en/reports.html>. [23 January 2018].

Sekar, V., Maniatis, P., 2011. Verifiable Resource Accounting for Cloud Computing Services. In: Proceedings of the 3rd ACM Workshop on Cloud Computing Security Workshop, CCSW '11. ACM, New York, USA, 21-26. DOI: 10.1145/2046660.2046666.

Trott, P., Hoecht, A., 2004. Enterprise Resource Planning (erp) and Its Impact on the Innovative Capability of the Firm. International Journal of Innovation Management 8, 381-398. DOI: 16.1142/S1363919604001118.

United Nations, n.d. UN E-Government Survey 2016. Available from: <https://publicadministration.un.org/egovkb/en-us/Reports/UN-E-GovernmentSurvey-2016>. [24 January 2018]. 
Singerová, J.: Accounting in Cloud.

Worster, A., Weirich, T. R., Andera, F., 2011. ERP systems: A lost opportunity. Journal of Corporate Accounting and Finance Wiley 22, 69-77. DOI: 10.1002/jcaf.20708. 